\title{
First optical seismometer at the Top of La Soufrière Volcano, Guadeloupe
}

\author{
R. Feron ${ }^{* 1,2}$, P. Bernard ${ }^{3}$, M. Feuilloy ${ }^{1,2}$, P. Ménard ${ }^{1}$, A. Nercessian ${ }^{3}$, S. Deroussi ${ }^{3,4}$, G.T Kitou ${ }^{3,4}$, and G. \\ Plantier ${ }^{1,2}$ \\ ${ }^{1}$ ESEO Group, Angers, France \\ ${ }^{2}$ Laboratoire d'Acoustique de l'Université du Mans, Le Mans Université, UMR CNRS 6613, Le Mans, France \\ ${ }^{3}$ Institut de physique du globe de Paris, Université de Paris, UMR 7154 CNRS, Paris, France \\ ${ }^{4}$ Observatoire volcanologique et sismologique de Guadeloupe, Institut de physique du globe de Paris, \\ Gourbeyre, France
}

\begin{abstract}
Accurate monitoring of volcanic activity demands expertise in fields including geophysics, geology, and geochemistry. Data obtained from the most recent technical advances are particularly vital in pre-eruptive phases. In particular, seismic monitoring in near real time is essential to locating and discriminating early signs among different sources of seismic waves, especially those related to movement and overpressure in underground fluids. Among themajor indicators of volcanic restlessness are fumaroles, or gas and steam vents, often located near a volcanic summit. Their activity could bemonitored by seismometers in their vicinity, but today's standard instruments cannot last very long when exposed to the high temperatures and the billowing, sulfurous, acidic gases near a fumarole. Conventional gear may also not be accessible for emergency deployment, or repair, even in pre-eruptive phases. La Soufrière de Guadeloupe Volcano in the Caribbean typifies such challenges. Its last significant event was a phreatic (gas and steam) eruption in 1976 that prompted evacuation of the archipelago's nearby capital. Since early 2018, the 1467-meter-high stratovolcano has shown signs of increased activity. To provide a hardy, high-resolution monitoring system, we installed a recently developed type of seismometer just 10 $\mathrm{m}$ from a vigorous summit fumarole. The sensor is a purely opto-mechanical geophone that is interrogated through a $1.5 \mathrm{~km}$ fiber-optic cable by a remote, and thus it is a much safer optic-electronic system down
\end{abstract}

the volcano's flank. The ESEO Group and the Institut de Physique du Globe de Paris (IPGP) started development of this novel seismometer in 2008. The 2019 Guadeloupe installation is part of the HIgh PERformance SeISmometer (HIPERSIS) project (French Agence Nationale de la Recherche [ANR]). It is, to our knowledge, the first high-resolution optical seismometer ever installed on an active volcano or other active, hazardous zone. We report here the details of this installation, the means we are using for measurements, and our implementation strategy, and we share some of the first results. Such an optical seismometer, as well as a variety of other geophysical sensors built on the same principle, can be installed in a wide variety of sites with fibers up to $50 \mathrm{~km}$ long.

\section{Seismological Research Letters (2020) \\ Volume 91 (5): 2448-2457 \\ Emerging Topics Section \\ Please note that this is a copy of the final, accepted (post peer review) version of the manuscript. The publisher-authenticated version is available here : https://doi.org/10.1785/0220200126}

*Corresponding author: romain.feron@eseo.fr 


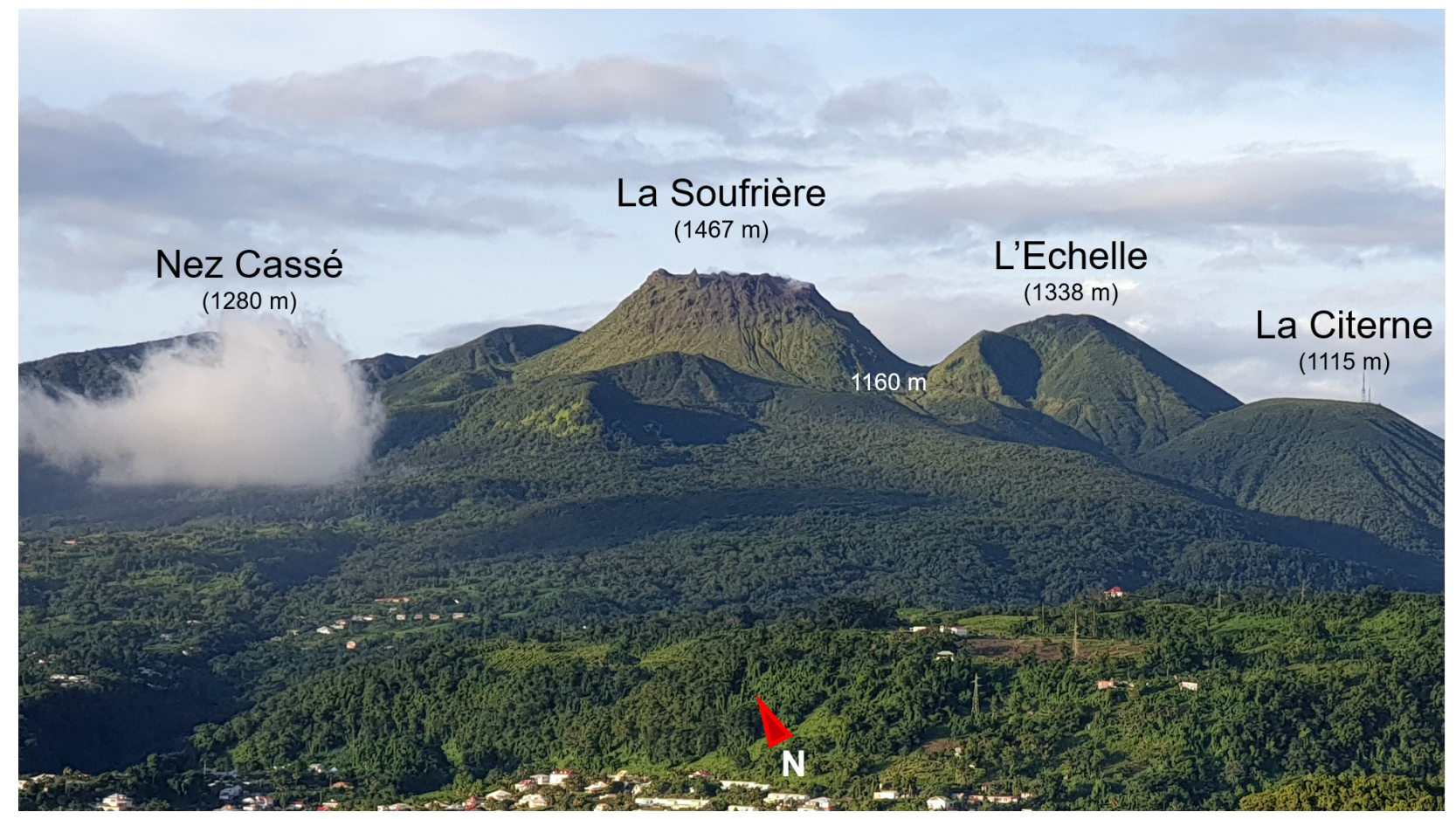

Figure 1: View of La Soufrière Volcano, from the Volcanological and Seismological Observatory of Guadeloupe (OVSG). White cylinder indicates the CSC (passive seismometer). Green triangle indicates OVSG's station LKG.

\section{Introduction}

In late September of 2019, a team including the authors climbed to the steaming, 1467-meter-high, lava-dome topped summit of La Soufrière, an active stratovolcano in the Guadeloupe archipelago in the eastern Caribbean Sea's Lesser Antilles. After two weeks, we had installed a new kind of seismometer on the mountain just $10 \mathrm{~m}$ from an active vent or fumarole; it was built to withstand extreme conditions that would rapidly destroy conventional instruments. So far it is working well.

This article describes the instrument in detail. It is important first to review the overarching reasons that Earth scientists devise and deploy such things.

Studying and monitoring the internal structures and activities of volcanoes is essential. It reveals why and how they erupt and helps us better anticipate such potential disasters. This requires many technical approaches born from fields including geophysics, geology, and geochemistry.

Specifically, seismic monitoring allows researchers to locate and characterize varied sources of seismic waves. These include ground ruptures (volcanotectonic events), oscillation in fluidfilled cracks (tremors and low-frequency events), explosions, or pressure fluctuations of gas emission through fumaroles. Many of these sources are concentrated near summits where hydrothermal processes often express themselves. The small amplitude of many locally significant vibrations requires that sensors be very close to fumaroles. Brutal environmental conditions include high temperature, humidity, and severe acidity. Other technical challenges are common near summit fumaroles. Power for conventional equipment is hard to arrange. Solar panels on site are unlikely to survive for long. Such locales make it dangerous or impossible to maintain sensors during explosive, eruptive phases. Kilometer-scale electrical cables can separate a safely remote recording system from local, robust sensors on active summits. However, the high risk of lightning may make external electric power too unreliable for long-term monitoring.

The French Volcanological and Seismological Observatory of Guadeloupe (OVSG) is responsible for monitoring regional tectonic activity in the Caribbean subduction zone (Fig. 1). A special focus is on La Soufrière, which epitomizes the difficulties that active volcanoes pose for seismology. It dominates the view to the north from Basse Terre, Guadeloupe's capital city and the observatory's home (Basse Terre is also the name of the island). A prime duty of the observatory staff is to notify Civil Protection authorities of any increase in hazard linked to volcanic activity.

The authors' affiliated organizations including ESEO 


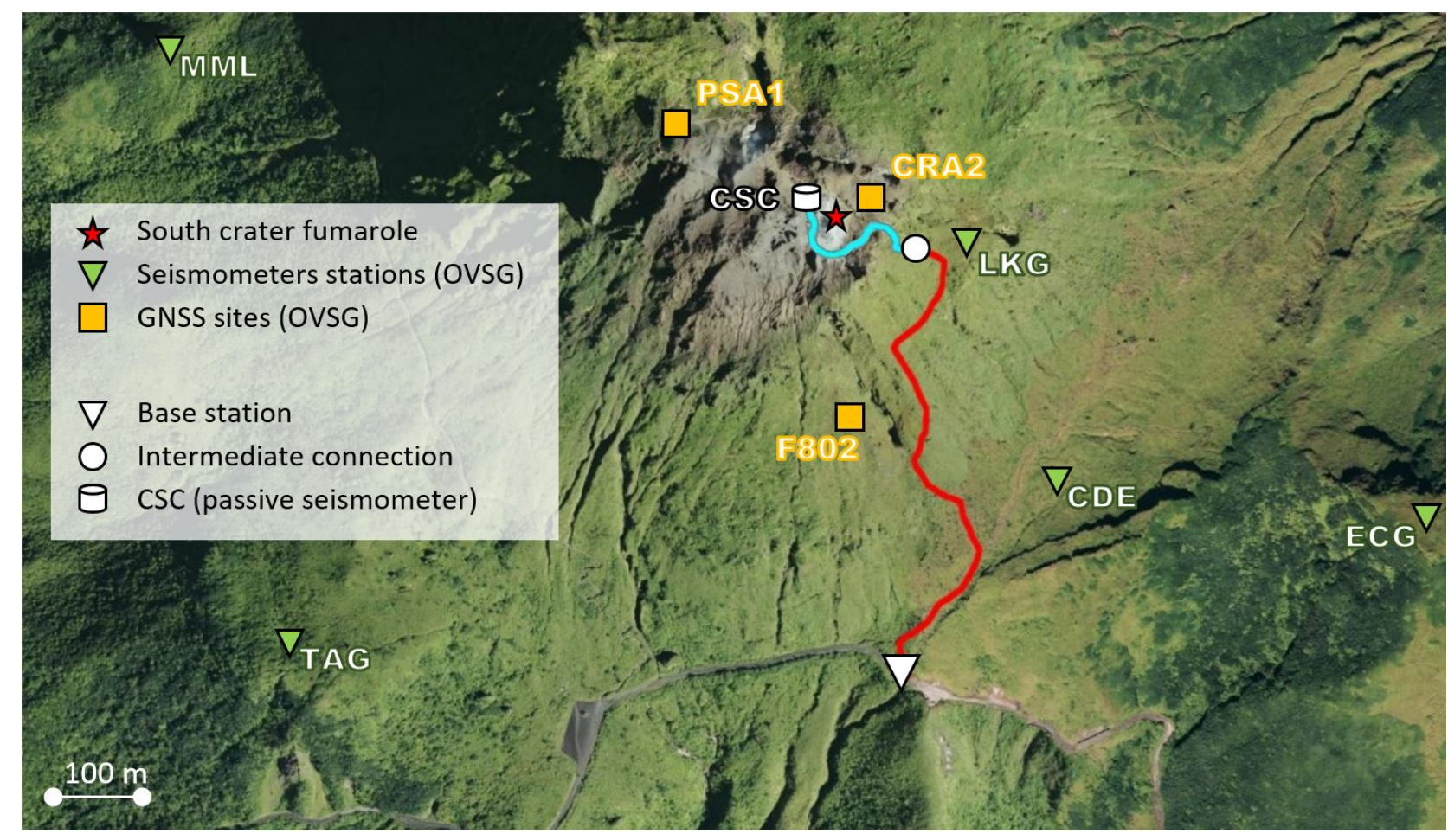

Figure 2: Part of OVSG's Soufrière network and Global Positioning System (GPS) location of our equipment. Red line is the long optic cable $(1500 \mathrm{~m})$, and blue line is the short optic cable designed for the harsh environment of the summit (150 m). GNSS, Global Navigation Satellite Systems.

and Institut de Physique du Globe de Paris (IPGP) have been working together for about $10 \mathrm{yr}$ to develop optical seismic sensors and systems able to withstand hostile environmental conditions (Bernard et al. (2017); Bernard et al. (2019b); Bernard et al. (2019a)). We developed our latest prototype and the topic of this report as part of the HIgh PERformance SeISmometer (HIPERSIS) project (French ANR). The project chose this collaboration's bid to put a permanent installation at La Soufrière. Although our optical seismometers have already been tested in rather protected environments (Chery et al. (2012)), with 3kilometer- long fibers, and in natural environments during an underwater measuring campaign (Brest, France) (Bernard et al. (2019b)), this is the first time one is in a critical area and exposed to immediate natural hazards.

The new station in the OVSG network is named CSC (Fig. 2). The large variety of sensors and recorders already in the region includes seismometers, Global Navigation Satellite Systems (GNSS) antennae, strainmeters, temperature, and gas and ground water sampling sites for geochemistry. This system feeds "WebObs," an integrated web-based platform for the observatory's network management and monitoring system (Beauducel et al. (2020)). Cross-analysis of the data, transmitted and processed in real time, bolsters both understanding of the internal struc- ture of the volcano and its ongoing activity. The most common hazards are from phreatic (gas and steam) eruption and volcanotectonic activity such as earthquakes due to fault movements (Tamburello et al. (2019)). The most recent phreatic eruption of La Soufrière lasted from 8 July 1976 to March 1977. It led to the evacuation of the city of Basse-Terre $(25,000$ people left spontaneously as the activity began, and another 73,422 were ordered away under emergency planning authority on 15 August 1976) (Komorowski et al. (2005)). To the surprise of experts, the volcano then settled into a quieter phase. It entered another round of unrest in early 1992 as temperature and degassing at the fumaroles increased.Most recently, volcanotectonic activity near the summit intensified in 2014. It generated mostly unfelt microearthquakes but included one magnitude 4.5 earthquake on 27 April 2018 (Moretti et al. (2020)).

\section{The Opto-Mechanical Seismometer}

The monitoring network includes four short-period and 11 broadband seismometers near the summit and at larger distances (Fig. 2). For reasons cited previously, no permanent seismometer is on the bare and near lifeless summit. 


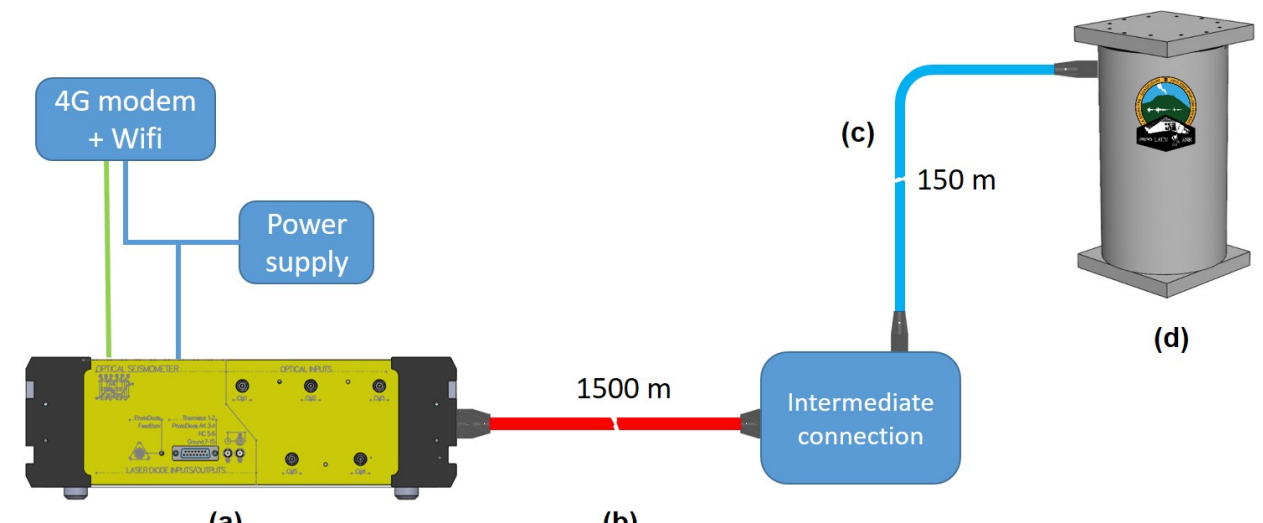

(a)

(b)

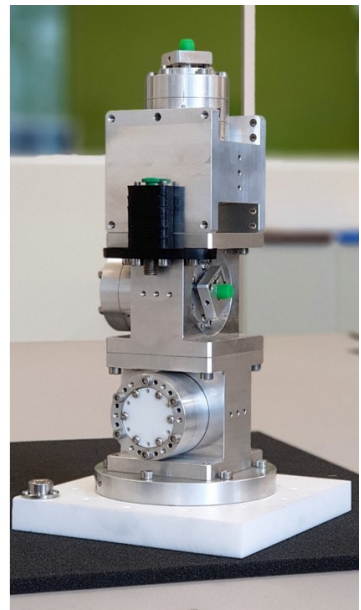

(e)

Figure 3: View of the entire system. (a) Optical interrogator Gaia- 4x; (b) long optic cable; (c) high temperature optic cable; (d) passive geophones in their sealed enclosure; (e) internal view of the seismometer: the three passive geophones and a reference termination (black central part).

Getting people very close to the fumarole vents to carry out specific measurements is another challenge due to the dangerous atmosphere and a ground temperature that may reach $100^{\circ} \mathrm{C}$.

The main fumaroles near the top of the volcano are a critical but previously almost untapped source of information (Allard et al. (2014)). Through their behavior, scientists can infer changes in the internal structure of the edifice. They can also gain insight into deep magmatic flows and their interaction with underground hydrothermal systems, mainly by monitoring the temperature, speed, and geochemistry of the gas released at the fumaroles. At present, these data including temperature and gas samples are regularly gathered manually in situ. This means not only that important information is not available in real time, but also that it is almost impossible to get any information at all during a crisis. The area becomes inaccessible for safety reasons. Local seismometers or microphones could in some limited instance monitor fumarole activity but, as explained earlier, not as permanent systems.

Now we present the characteristics of our seismometer and the general plan of the system, review the steps of the installation process, and discuss a few preliminary findings that characterize the system's strengths.

The optical seismometer is based on Fabry-Perot interferometry. Each axis of measurement depends on the short space between the termination of a glass fiber emitting infrared laser radiation on one end and, on the other, a reflecting mirror on the mobile mass of a passive geophone (Seat et al. (2012)). The space between the mirror and glass fiber is the optical cavity, or Fabry-Perot interferometer proper.
The fiber carrying both the arriving signal and its returning reflection connect to an electro-optical system or interrogator. It has $1310 \mathrm{~nm}$ laser diodes as the beam sources. Photo diodes receive its return laser beams. ESEO provided an interrogator for signal analysis at the other end of a $1.5 \mathrm{~km}$ fiberoptic cable (Fig. 3). The interrogator and the interferometry it controls calculate ground displacement $\mathrm{D}(\mathrm{t})$ at each seismometer as earthquake waves and other surface and underground waves pass through. The mobile masses tend to remain stationary, whereas the infrared laser sources at the ends of the fibers, coupled to the ground, move. To boost measurement accuracy, the interrogator modulates the wavelength of the laser diode at a rather high frequency Fm $(50 \mathrm{kHz})$. The cosine spectrum of $\mathrm{D}(\mathrm{t})$ is actually centered on Fm, whereas the sine spectrum of $D(t)$ is centered on $2 \times F m-$ the first harmonic of Fm. Information is derived in part by a double synchronous demodulation. The instantaneous phase of resulting, clarified signals contains a signature of the displacement. To decipher it, a real-time adaptive estimation algorithm (Kalman filter) followed by a phase unwrapping yields the distance $\mathrm{D}(\mathrm{t})$ of the mobile mass from the other side of the optical cavity (Chawah et al. (2012)). This seismometer and signal analysis presents very high-resolution characteristics, similar to those of the best commercial short period or medium band seismometers (Bernard et al. (2019b)) and to the optical seismometers of Zumberge et al. (2010) (based on Michelson interferometry).

Other technologies involving optical fiber are already used in the field of geophysics. Some of them are based on the backscattering properties of the fiber itself-the fiber is 


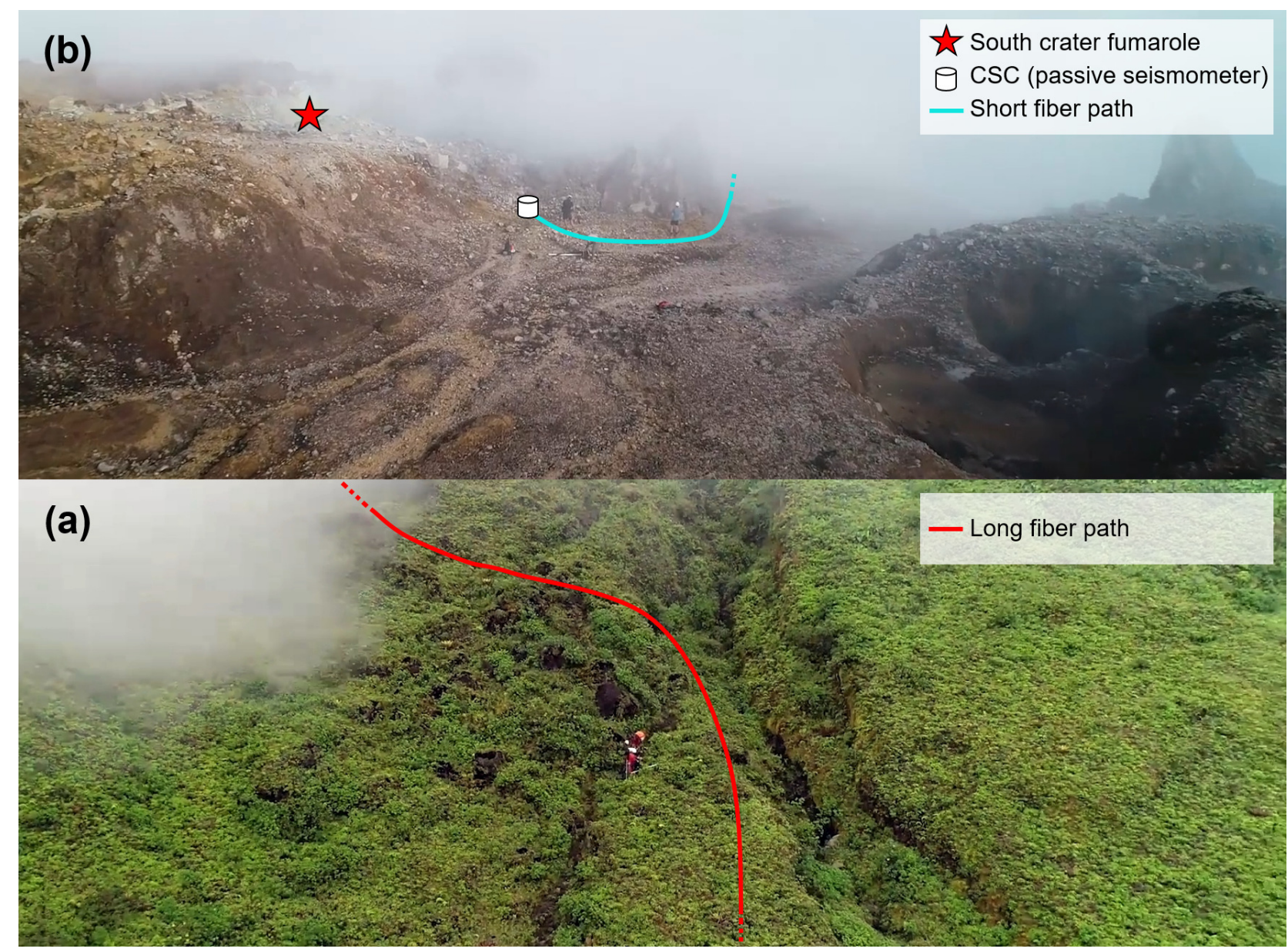

Figure 4: (a) Summit area of the volcano, bare of vegetation due to the acidic environment. Seismometer is under the smoke plume of the fumarole. (b) Long fiber installation along the luxuriant flank of La Soufrière Volcano. The team is moving along the path (center), laying the cable on the vegetation.

actually the sensing part. Among these techniques is distributed acoustic sensing (DAS; e.g., Jousset et al. (2018); Zhan (2020)), now fully operational, which provides thousands of dynamic strain sensors along a single fiber. This high number of measurements gives DAS a considerable advantage over extrinsic interferometry with, as in our instrument, a single sensor per fiber. DAS measurements, however, present much higher instrumental noise. They also pose difficulties for calibration due to the very high spatial variability of strain coupling to the ground all along the fiber. Clearly, intrinsic systems such as DAS and extrinsic systems such as our seismometer have complementary advantages. They could well be combined on the same cable or cable bundle to fully exploit the potential of optical fibers.

The mechanical part of our sensor does not contain any electronic system, thereby evading the usual temperature vulnerabilities of standard electronic systems. The geophones and their container were specifically designed and manufactured for La Soufrière installation. This includes a tolerance of temperatures of up to $125^{\circ} \mathrm{C}\left(257^{\circ} \mathrm{F}\right)$ and the very high acidity expected near fumaroles.

The material of the casement is entirely polytetrafluoroethylene (PTFE), commonly called Teflon. It is well known to be particularly resistant to sulfuric gases. Such engineering produced a very sturdy instrument. It is essentially oblivious to any natural assault short of a flood of acidic fluid, slope-collapse landslide, or major explosion.

Each of the three sensor axial components is connected to one optical fiber, and a fourth fiber provides a reference optical signal, primarily to correct shared background optoelectronic noise. The mechanics of the geophones (baptized "Geophone HIPersis [GHIP]") used for this pilot installation were entirely conceived and developed within the scope of ANR HIPERSIS: three simple $10 \mathrm{~Hz}$ oscillators mounted on spider springs. The structure is then fitted to a trihedral in a waterproof container able to withstand the previously mentioned environmental conditions. This 10 
$\mathrm{Hz}$ natural frequency is high enough to withstand sudden motions while leveling or accidentally rotating the container-which could lead to themechanical clipping of oscillators with lower natural frequencies (typically 1,2 , and $4.5 \mathrm{~Hz}$ ). As no electronics is involved in the container, the oscillators are fully passive. Because their natural damping is very weak, we employed a damping system based on eddy currents. We opted for samarium-cobalt annular magnets for their useful magnetic properties and particularly for their behavior as temperature changes. This choice not only stiffens the seismometer but also allows us to estimate the mobile mass position relative to the gravitational acceleration vector in case of rotation of the sensor container. We expect to deepen discussion of these mechanical oscillators in a later communication.

The optical cable designed for this particular installation is split into two segments. It enables the connections between the mechanical part at the summit and the optical interrogator, located $500 \mathrm{~m}$ lower in altitude. The main part, or "long fiber," is deployed along the side of the volcano from the optical interrogator up to near the top of the volcano. This long fiber connects the optical interrogator to an intermediary connection point located right under the dome of La Soufrière (Fig. 2). It holds eight single-mode optical fibers: four continuing toward the sensor located near the fumarole and four in reserve for additional sensors. The lower stretch of cable was specifically treated to resist any potential damage caused by abrasion and rodents. The second part, named "short fiber," reaches the seismometer from the intermediary connection point and is even more robust for it must withstand summit conditions; it is protected from the acidic gasses and water by a PTFE coating. The intermediary connection point is made of a waterproof- shielded case containing all of the optical connections and the stubbed-off spare fibers. This will allow the installation of other sensors from this point.

\section{The Setting of La Soufrière Installation}

\section{Installing the base station}

We installed the base station 27-29 September 2019, at the bottom of the dome, located $500 \mathrm{~m}$ lower in elevation than the summit (Fig. 2). Most important, it includes the interrogator, the core brains of the system. It has all of our installation's optoelectronic systems and the real-time signal processing unit. Solar panels, and their system of load regulation, are on a separate structure at the same site. Their output is stored in batteries to enable operation day and night. The system with four working optical chan- nels requires about $30 \mathrm{~W}$ for optimal performance. It has two wireless communication devices. A $4 \mathrm{G}$ modem allows us to remotely monitor signals. A Wi-Fi antenna has also been installed to eventually allow the OVSG ( $8 \mathrm{~km}$ away) direct access to the data.

\section{Laying down the long fiber on the slope}

Installation of the cable (Fig. 4a) required particular attention due largely to local flora. La Soufrière is in a protected area managed by the National Park of Guadeloupe. The optical cable, in $40 \mathrm{~kg}$ segments carried on our backs up the narrow and steep footpath, was carefully laid on and through brushy, thick vegetation a few meters away from the path. Several points have about $5 \mathrm{~m}$ of looped, slack cable distributed along the route to allow adjustment for changes in local mechanical strain. Stretches that appear vulnerable to damage during the frequent storms were braced with metal bars or conduits.

Furthermore, two types of long fiber-loose tube or tight buffered - were test-deployed to check whether mechanical stresses within the optic cable affect our measurements. We worried in particular about vibration of the cable in strong winds. We speculated that loose optic cable might be less sensitive to external mechanical stress than the tightbuffered version because fibers can move more freely within the tube thanks to its internal structure.

\section{Installing the seismometer and the short fiber at the summit}

The team wore gas masks to tolerate acrid fumes from fumaroles during most of the installation of the summit seismometer and of the closely adjacent segment of the short fiber. We installed the seismometer about $10 \mathrm{~m}$ to the northwest of the central fumarole of the south crater. We leveled it, aligned it to geographic north, and completely buried it-its base is about $80 \mathrm{~cm}$ down-within the clayrich soil left by decomposition of volcanic rock. Moreover, we installed a reference seismometer (Trillium Compact $120 \mathrm{~s}) 1 \mathrm{~m}$ away in the same sort of ground to cross-check the performance of our system. We removed this reference instrument after three weeks to stop the acidic atmosphere from damaging the sensor, the recorder, and the solar panels.

After burying the seismometer, we laid the short cable connected to it in a narrow and shallow trench $(20 \mathrm{~cm}$ broad, $20 \mathrm{~cm}$ deep), dug into the soft and altered soil of the summit area, and covered it with soil or paved it with stones (Fig. 4b). The cable had to span a deep depres- 

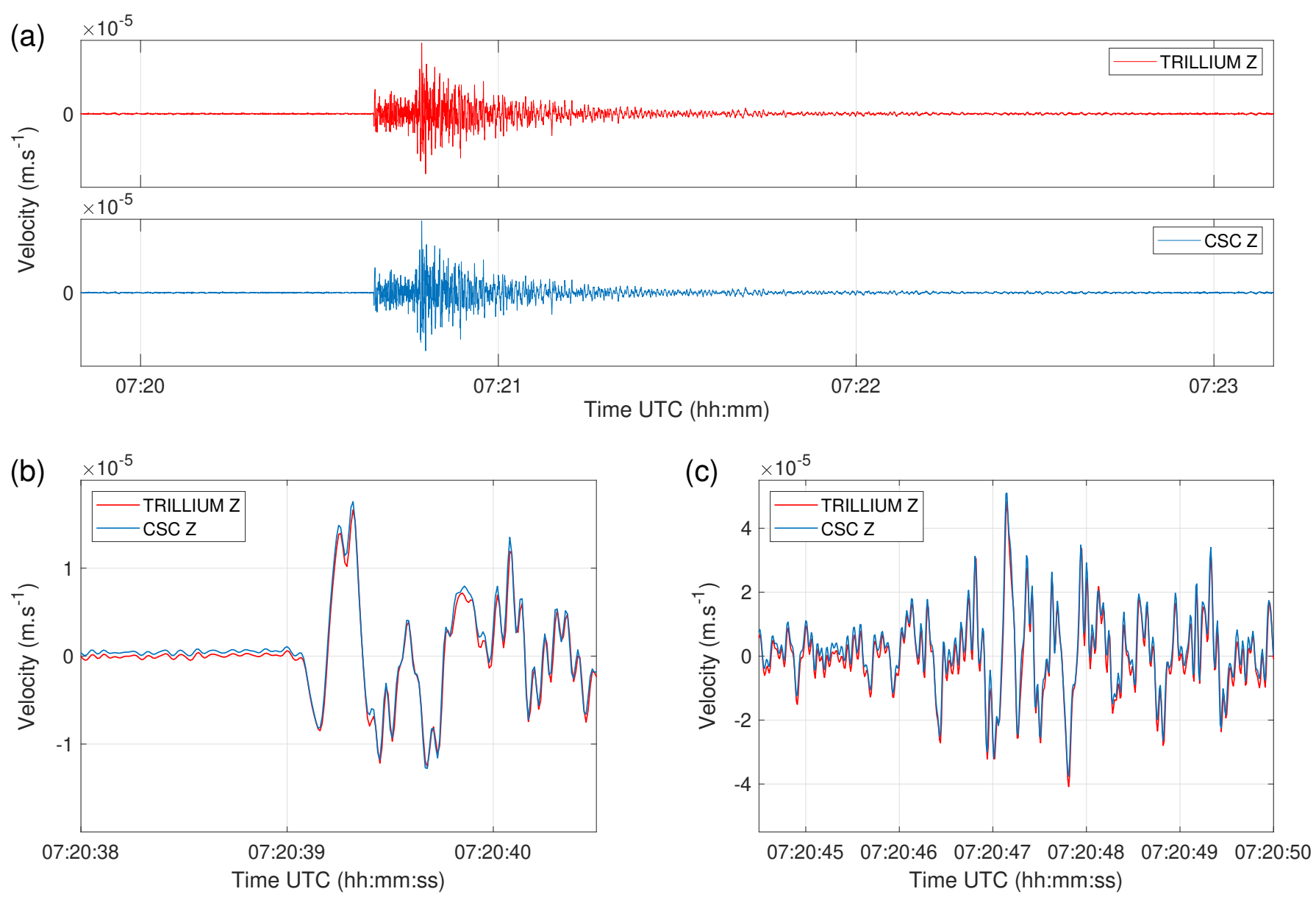

Figure 5: Records of the 25 October 2019 Mw 4.1 Le Moule, Guadeloupe, earthquake from the CSC station and Trillium reference seismometer (vertical channel). Data are filtered in the [0.5-20] Hz range. (a) Vertical ground velocity, (b) P-wave arrival, and (c) S-wave arrival. Signals of CSC are slightly shifted upward on $(b, c)$.

sion in the dominant direction of a powerful fumarole jet. We encased the aerial part of the cable in a 10-meter-long polyvinyl chloride conduit. About $150 \mathrm{~m}$ away from the seismometer, the cable meets the steep slope of the volcano. From there, we laid it in low but thick vegetation to be connected to the upper terminus of the long main cable, located $50 \mathrm{~m}$ down the slope on the southeastern flank.

The short upper cable has a PTFE outer coating able to withstand temperatures up to $150^{\circ} \mathrm{C}\left(302^{\circ} \mathrm{F}\right)$ and high acidity around the summit of the volcano. To avoid damage to the instrument by lightning strikes, the cable has no metal.

\section{Preliminary Results}

After a few months of operation, we had enough data for preliminary evaluation of the system's performance.

Recordings of two relevant earthquakes, Figures 5 and
6 , illustrate the broadband capabilities of our seismometer station. The first signal was from a regional subduction earthquake on 25 October 2019. Its moment magnitude or Mw was 4.1 at a depth of 17 and $55 \mathrm{~km}$ away. Figure 5 shows the $\mathrm{P}$ - and $\mathrm{S}$-wave arrivals recorded by both seismometers: the reference Trillium C 120 s and CSC, corrected for instrumental response and sensitivity. The signals are filtered to include only the [0.5-20] Hz range, in which this moderate seismic event put most of its energy. One can clearly note a very good match between them, including the background microseismic noise before the P-wave arrival.

To assess the quality of the measurements at periods longer than $1 \mathrm{~s}$, we analyzed the recording of a 29 October Mw 6.8 Chile earthquake. At such long or teleseismic distances, the Earth naturally filtered out high frequencies. The remaining wavelengths were large enough to present 

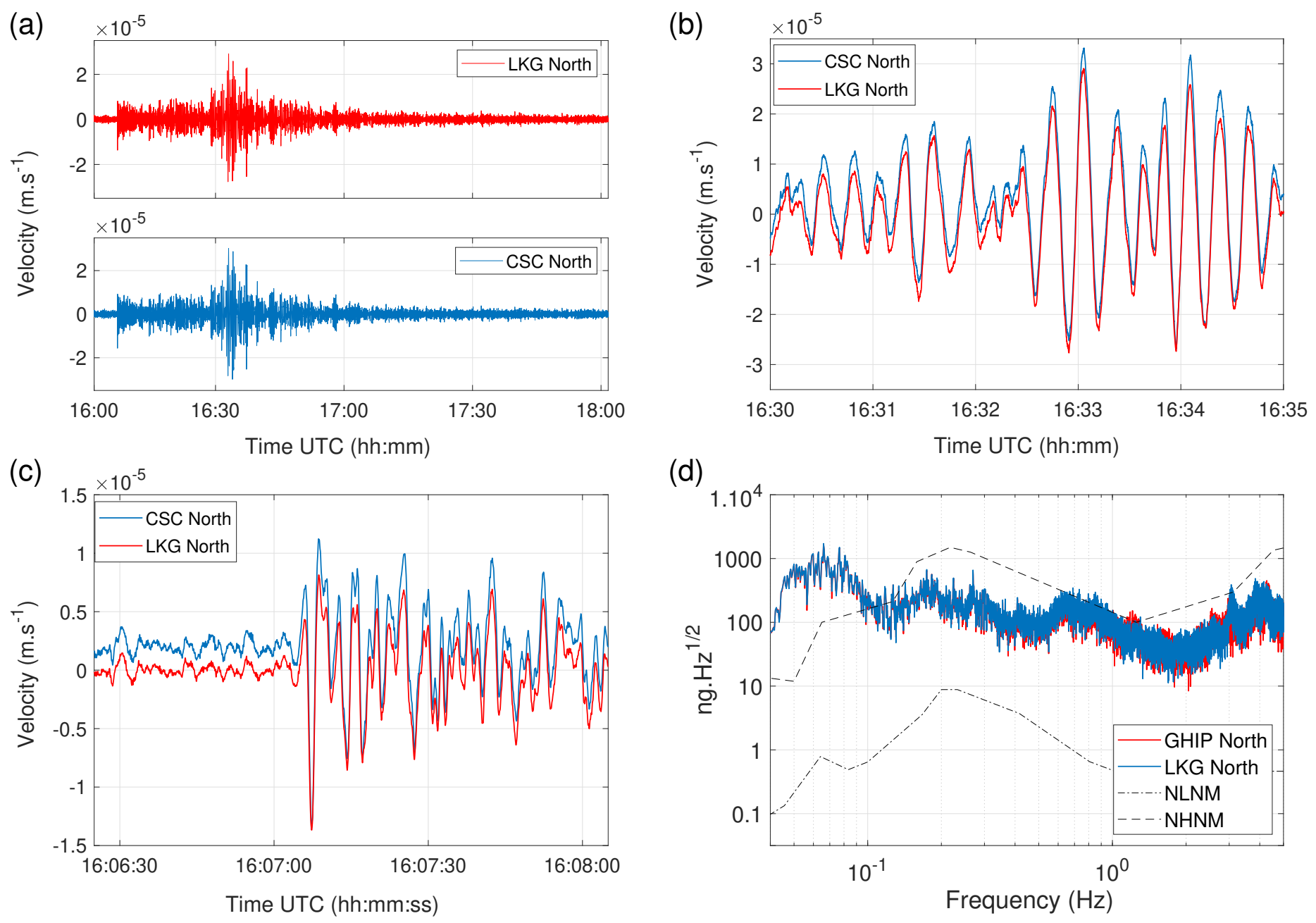

Figure 6: Records of the 29 September 2019 Mw 6.8 Chile earthquake from the CSC station and the LKG station (see Data and Resources). Data are filtered in the [0.05-5] Hz range. (a) North ground velocity and (b) 15 min of north ground velocity showing the dominant surface waves. (c) About 2 min of north ground velocity near the P-arrival time and (d) acceleration spectra. Black dashed curves, new low-noise model and new high-noise model (Peterson (1993)). Signals of CSC are slightly shifted upward on (b,c). .

to the CSC and our reference seismometer almost identical ground motions. Signals are filtered in the period range from 0.2 to $20 \mathrm{~s}$ ([0.05-5] Hz frequency range) (Fig. 6). The match between the temporal waveforms is still very good for periods as low as $20 \mathrm{~s}$, and the spectral amplitude remains similar in the $1-5 \mathrm{~Hz}$ domain.

The first data pertinent to justifying monitoring La Soufrière are shown in Figure 7. They are from a 2 December sequence of earthquakes centered less than 2.5 $\mathrm{km}$ directly beneath the volcano summit. These are signals, filtered to include only the [1-20] $\mathrm{Hz}$ range, from our new seismometer and two OVSG stations. The latter are designated LKG, located $200 \mathrm{~m}$ away from CSC, and MML, located about $1 \mathrm{~km}$ away (Fig. 2). According to the OVSG report, the observatory recorded 229 earthquakes of very low magnitude $(\mathrm{Mw}<1)$ between 30 November and 5 December (OVSG-IPGP (2019)). Ten seismic stations including MML provided data. Our sensor, buried right at the summit, detected about $25 \%$ of the microearthquakes identified by OVSG. This fairly low detection rate is caused by the high-noise interference of the nearby fumarole. This is clearly apparent in Figure 7, which shows a much higher root mean square noise at CSC than at MML - though similar to that of LKG. Despite this strong ambient noise, continued operation of our seismometer at this site should significantly improve the ability to locate events that it detects, most notably their depths (eased by being above the sources) and hence improve the global performance of the monitoring system of OVSG. Again, operating at this location with a conventional com- 

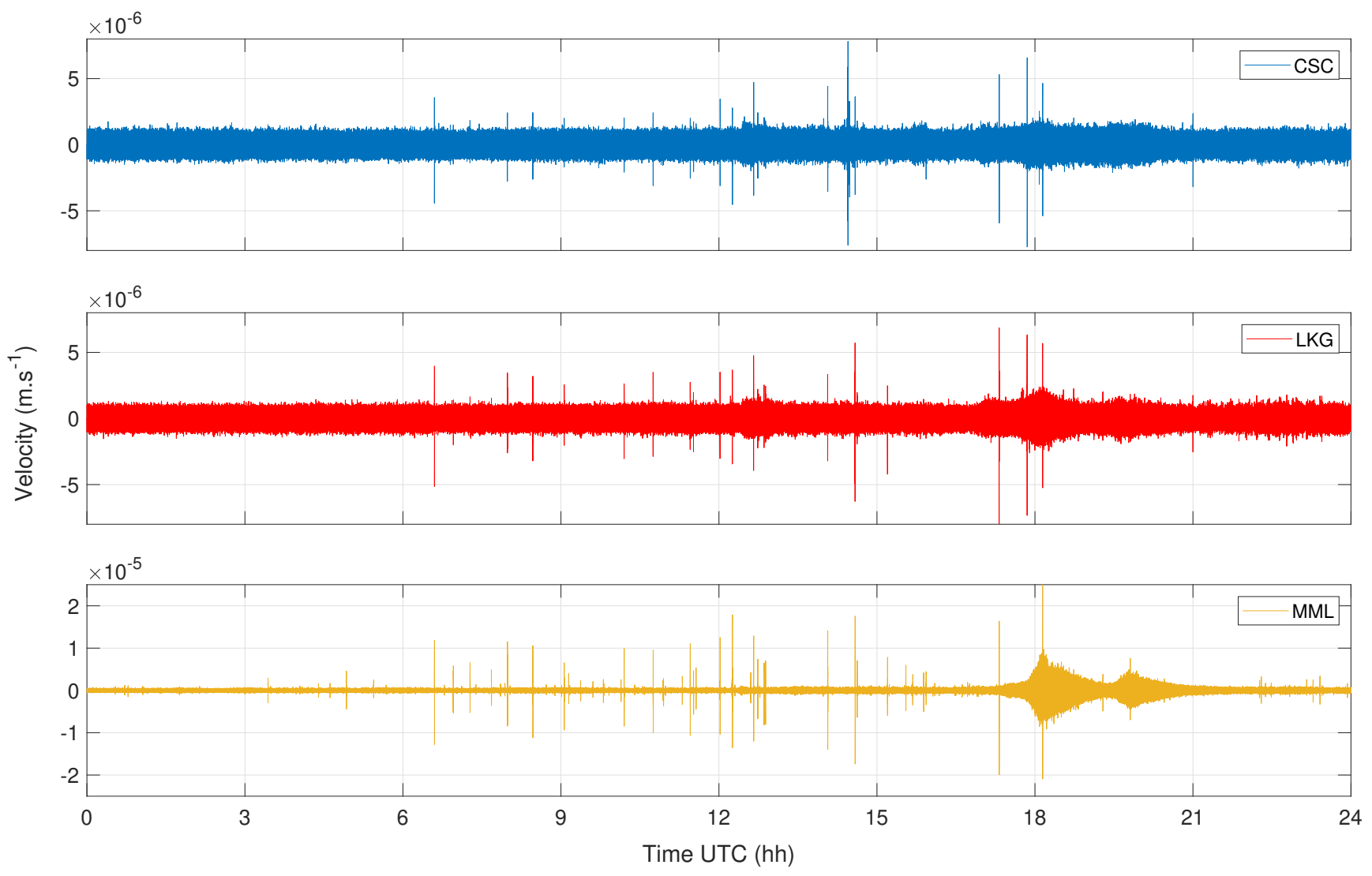

Figure 7: Sequence of volcanic earthquakes. East channels records of OVSG's stations_LKG and MML (see Data and Resources) - and CSC station. Data are filtered in the [1-20] Hz range. The high-level noise caused by the fumarole is visible on CSC and LKG signals.

mercial, electrically powered seismometer would not be possible in the long run.

A second category of observation relates immediately to why we put the seismometer where we did: vibrations from fumarole activity. We found them to be dominant around $4 \mathrm{~Hz}$. The proximity of the CSC station to the main fumaroles provides an additional picture of the variation of this frequency over time plus overtones and in a different manner than the nearest permanent LKG station (150 $\mathrm{m}$ away) does. We illustrate this in Figure 8, which shows the spectral evolution in time of CSC north (Fig. 8a) and LKG north (Fig. 8b). Sweeps and jumps in frequency, as well as distinctly unrelated frequency trends, suggest multiple sources and a complex, unstable pressurization of gas in a hydrothermal system, the detail of which is yet to be mapped or modeled (e.g., Giudicepietro et al. (2019)). For instance, one notes that the energy ratio of the $6.2 \mathrm{~Hz}$ peak to the $3 \mathrm{~Hz}$ peak is very small at CSC relatively to that at LKG. This strongly suggests a source of the $3 \mathrm{~Hz}$ peak that is much closer to CSC, possibly related to the nearby fu- maroles-which is not the case for the $6.2 \mathrm{~Hz}$ source probably located much deeper. A detailed study of these signals is beyond the scope of this article. Nonetheless, preliminary observations already show that this new permanent source of information close to the fumarole may help constrain the geometry and activity of the plumbing system of the geothermal dome and model its internal processes.

Returning to measurement reliability, the type for optical cable (loose tube or tight buffered) does not seem to have a significant impact even though this cable is prone to shaking from strong winds over most of its length. This, we conclude, is a direct consequence of the use of the same fiber for both ingoing and outgoing beams, as follows from the Fabry-Perot design of the interferometer. This confirmed behavior is very important for deployment planning, even offshore. Indeed, with a 50-kilometer-long cable, ground motion from an earthquake can shake a long segment of it much more vigorously than it can the optical seismometer at the end of the line. The outcome of the presented experiment, with its strong wind buffeting of 
the exposed part of the cable (about $800 \mathrm{~m}$ long) and with very small vibrations at the sensor location, demonstrates that it matters little whether the cable is loose in the tube or tightly restrained.

We do not yet have enough experience to assert full confidence in the long-term endurance of optic cables on the volcano. But, one hopes that slow degradation of the fiber, whatever its cause (mechanical through flexure or traction, or chemical with water of hydrogen infiltration), will affect only its optical attenuation and hence the signal-to-noise ratio, but neither the sensitivity nor the spectral response of the seismometer.

\section{Conclusion}

For the very first time, an optical seismometer at the end of a long fiber is on a site of keen interest for geophysicists: La Soufrière Volcano, Guadeloupe. The advantages of such an optical installation on an active volcano result from the separation of an opto-electronics interrogator set in a remote and safe place from an opto-mechanical sensor within the active zone. The absence of electrical power at the sensor considerably reduces the possible causes of failure: no electronics, no batteries, and no solar panels. This ensures the continuity of remote monitoring when maintenance and repair visits are not possible because of volcanic activity. However, it is important to note that the installation of such a solution is also more complex and requires much more time than what it takes to deploy a standard seismometer. Other main drawbacks are the possibly difficult laying or burying of the optical cable on some volcanoes and its as yet unconfirmed long-term endurance.

Our work on La Soufrière is just started. We aimtomerge the information that our system provides with all of the multiparameter data that the OVSG gathers at the volcano. This will certainly improve our understanding of the mechanics of the volcano's internal processes and, in particular, of the fumarole signature and of other nearby sources of shallow seismicity. We will discuss these aspects in a further communication. In addition, we hope that similar stations at the summit of La Soufrière will provide sustained information during a crisis. The success of this operation, together with the development of tiltmeters and pressure gauges based on the same optical principle (Chawah et al. (2015)) by Ecole Normale Supérieure de Paris, opens the way to a wide variety of installations. The next one is scheduled for 2021, $5 \mathrm{~km}$ off Les Saintes Island, another part of the French Department of Guadeloupe. The bursts of microearthquakes that occur constantly in this area are still poorly located and poorly understood. But they do arise in a normal-fault system; it ruptured to generate a strong earthquake in $2004(\mathrm{Mw}=6.3)$. This project in Les Saintes aims at cabling on land and installing offshore three instruments (seismometer, pressure gauge, and tiltmeter), just above the shallow active swarms. It has two objectives, one scientific and the other technological: first to improve our understanding of this persistent activity and second to qualify an innovative optical, geophysical monitoring system offshore. One of the main advantages expected from the latter, compared with electrically powered offshore instruments, is much lower maintenance costs by having no electronics at the seismometer itself.

Other terrestrial and offshore targets are already under consideration thanks to the potential ability of our system to operate with optical cables up to $50 \mathrm{~km}$ long. As a medium-term ambition, our system could efficiently contribute to an offshore volcanic observatory planned mainly by IPGP for the French island of Mayotte in the Indian Ocean archipelago of the Comoros. This observatory will monitor exceptional submarine magmatic activity that started in 2018. Other marine targets have been well studied: in Greece (Patras-Corinth rift and western Peloponnesus subduction), in Italy (Campi Flegrei), and in Turkey (Marmara Sea), among many others. Hot boreholes, such as in the geothermal area of Campi Flegrei (Italy), are also attractive targets. These optical instruments also may be effective for monitoring geoindustrial sites such as oil and gas production fields, gas storage facilities, nuclear power plants and waste repositories, deep mines, and high temperature geothermal reservoirs. Actually, the design of many other optical geophysical sensors (hydrophones, microphones, strainmeters, gravimeters, and so forth) based on the same optical interrogator is under study, further boosting the diversity of monitoring capabilities.

\section{Data and resources}

The records of the LKG (Trillium Compact 120s) and MML (Trillium 40) stations, part of the GL network, are available on the French seismological and geodetic network (RESIF) Seismic Data Portal (http://seismology.resif.fr/, last accessed February 2020).

\section{Acknowledgments}

This study was supported by the Agence Nationale de la Recherche (ANR), France ("HIgh PERformance SeISmometer [HIPERSIS]” Project, 2016-2019). The HIPER- 
SIS project was certified by the Pôle AVENIA before submission to the ANR call. This study was also supported by the Regional Telluric Surveillance Platform project (PREST), part of the INTERREG-Caribbean. The authors particularly thank the staff of the Volcanological and Seismological Observatory of Guadeloupe (OVSG) for their support throughout the installation process and their help thereafter. The authors thank the Guadeloupe National Park, which authorized the installation of the system. The authors thank the reviewer for his meaningful comments, Roberto Longo and Irène Feron for their careful proofreading, Charles Petit for editing the article, and Editorin-Chief Allison Bent for inviting us to submit this contribution.

\section{References}

Allard, P., A. Aiuppa, F. Beauducel, D. Gaudin, R. Di Napoli, S. Calabrese, F. Parello, O. Crispi, G. Hammouya, and G. Tamburello

2014. Steam and gas emission rate from La Soufriere volcano, Guadeloupe (Lesser Antilles): Implications for the magmatic supply during degassing unrest. Chemical Geology, 384:76-93.

Beauducel, F., D. Lafon, X. Béguin, J.-M. Saurel, A. Bosson, D. Mallarino, P. Boissier, C. Brunet, A. Lemarchand, C. Anténor-Habazac, A. Nercessian, and A. A. Fahmi

2020. WebObs: The Volcano Observatories Missing Link Between Research and Real-Time Monitoring. Frontiers in Earth Science, 8.

Bernard, P., C. Brunet, A. Nercessian, A. Sourice, M. Feuilloy, R. Feron, M. Cattoen, H.-C. Seat, P. Chawah, and J. Chery

2017. The lines high resolution optical seismometer. In EAGE/DGG 2017, Potsdam.

Bernard, P., R. Feron, G. Plantier, A. Nercessian, J. Couteau, and M. Feuilloy

2019a. High resolution passive optical seismometer connected to a long fiber for onland and offshore remote applications. In EGU General Assembly, Viena, Austria, Viena.

Bernard, P., R. Feron, G. Plantier, A. Nercessian, J. Couteau, A. Sourice, M. Feuilloy, M. Cattoen, H. Seat, P. Chawah, J. Chéry, C. Brunet, F. Boudin, D. Boyer, S. Gaffet, L. Geli, and P. Pelleau 2019b. Onland and Offshore Extrinsic Fabry-Pérot Optical Seismometer at the End of a Long Fiber. Seismological Research Letters, 90(6):2205-2216.
Chawah, P., J. Chéry, F. Boudin, M. Cattoen, H. Seat, G. Plantier, F. Lizion, A. Sourice, P. Bernard, C. Brunet, D. Boyer, and S. Gaffet

2015. A simple pendulum borehole tiltmeter based on a triaxial optical-fibre displacement sensor. Geophysical Journal International, 203(2):1026-1038.

Chawah, P., A. Sourice, G. Plantier, H. C. Seat, F. Boudin, J. Chery, M. Cattoen, P. Bernard, C. Brunet, S. Gaffet, and D. Boyer

2012. Amplitude and Phase Drift Correction of EFPI Sensor Systems Using Both Adaptive Kalman Filter and Temperature Compensation for Nanometric Displacement Estimation. Journal of Lightwave Technology, 30(13):2195-2202.

Chery, J., F. Boudin, H.-C. Seat, M. Cattoen, P. Chawah, G. Plantier, A. Sourice, and C. G. S. Bernard, P.and Brunet

2012. Detecting aseismic transient motion on faults using new optical tiltmeters and seismometers. In $A G U$ Fall Meeting, San Francisco, California.

Giudicepietro, F., G. Chiodini, S. Caliro, W. De Cesare, A. M. Esposito, D. Galluzzo, D. Lo Bascio, G. Macedonio, M. Orazi, P. Ricciolino, and J. Vandemeulebrouck 2019. Insight Into Campi Flegrei Caldera Unrest Through Seismic Tremor Measurements at Pisciarelli Fumarolic Field. Geochemistry, Geophysics, Geosystems, 20(11):5544-5555.

Jousset, P., T. Reinsch, T. Ryberg, H. Blanck, A. Clarke, R. Aghayev, G. P. Hersir, J. Henninges, M. Weber, and C. M. Krawczyk

2018. Dynamic strain determination using fibre-optic cables allows imaging of seismological and structural features. Nature Communications, 9(1):2509.

Komorowski, J.-C., G. Boudon, M. Semet, F. Beauducel, C. Anténor-Habazac, S. Bazin, and G. Hammmouya 2005. Volcanic Hazard Atlas of the Lesser Antilles: Guadeloupe. In Volcanic Hazard Atlas of the Lesser Antilles, J. Lindsay, S, Robertson, J, Shepherd, R, Ali, ed., chapter Guadeloupe, Pp. 65-102. University Of The West Indies.

Moretti, R., J.-C. Komorowski, G. Ucciani, S. Moune, D. Jessop, J.-B. de Chabalier, F. Beauducel, M. Bonifacie, A. Burtin, M. Vallée, S. Deroussi, V. Robert, D. Gibert, T. Didier, T. Kitou, N. Feuillet, P. Allard, G. Tamburello, T. Shreve, J.-M. Saurel, A. Lemarchand, M. Rosas-Carbajal, P. Agrinier, A. Le Friant, and M. Chaussidon

2020. The 2018 unrest phase at La Soufrière of Guadeloupe (French West Indies) andesitic volcano: Scrutiny of a failed but prodromal phreatic eruption. Journal of 
Volcanology and Geothermal Research, 393:106769.

OVSG-IPGP

2019. Monthly Public Report of Guadeloupe's Volcanic and Seismic Activity (2019). Technical report, OVSGIPGP.

Peterson, J.

1993. Observations and modeling of seismic background noise. Technical report.

Seat, H. C., P. Chawah, M. Cattoen, A. Sourice, G. Plantier, F. Boudin, J. Chéry, C. Brunet, P. Bernard, and M. Suleiman

2012. Dual-modulation fiber Fabry-Perot interferometer with double reflection for slowly-varying displacements. Optics Letters, 37(14):2886.

Tamburello, Moune, Allard, Venugopal, Robert, RosasCarbajal, Deroussi, Kitou, Didier, Komorowski, Beauducel, DeChabalier, Le Marchand, Le Friant, Bonifacie, Dessert, and Moretti

2019. Spatio-Temporal Relationships between Fumarolic Activity, Hydrothermal Fluid Circulation and Geophysical Signals at an Arc Volcano in Degassing Unrest: La Soufrière of Guadeloupe (French West Indies). Geosciences, 9(11):480.

Zhan, Z.

2020. Distributed Acoustic Sensing Turns Fiber Optic Cables into Sensitive Seismic Antennas. Seismological Research Letters, 91(1):1-15.

Zumberge, M., J. Berger, J. Otero, and E. Wielandt 2010. An Optical Seismometer without Force Feedback. Bulletin of the Seismological Society of America, 100(2):598-605. 
(a)

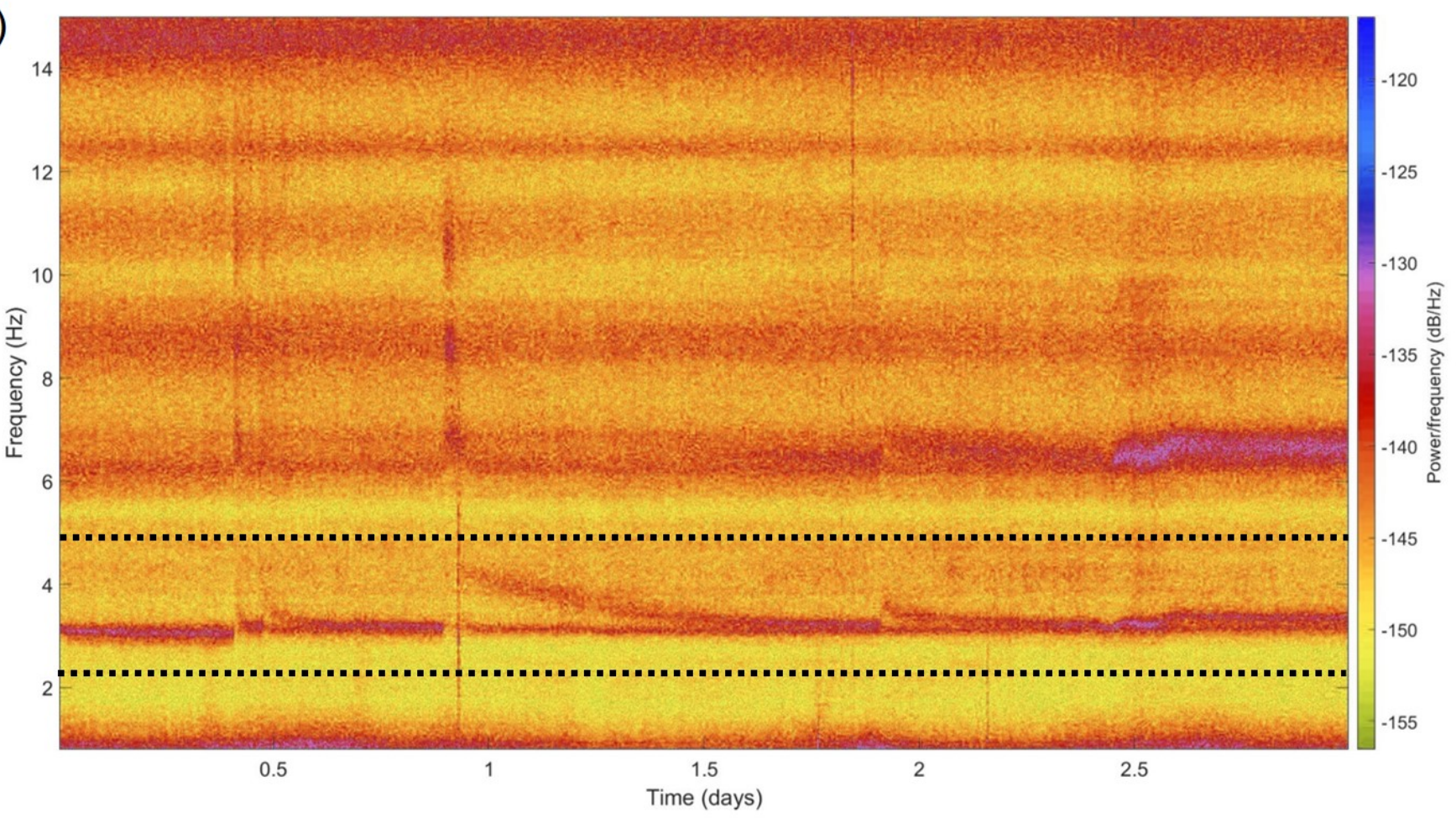

(b)

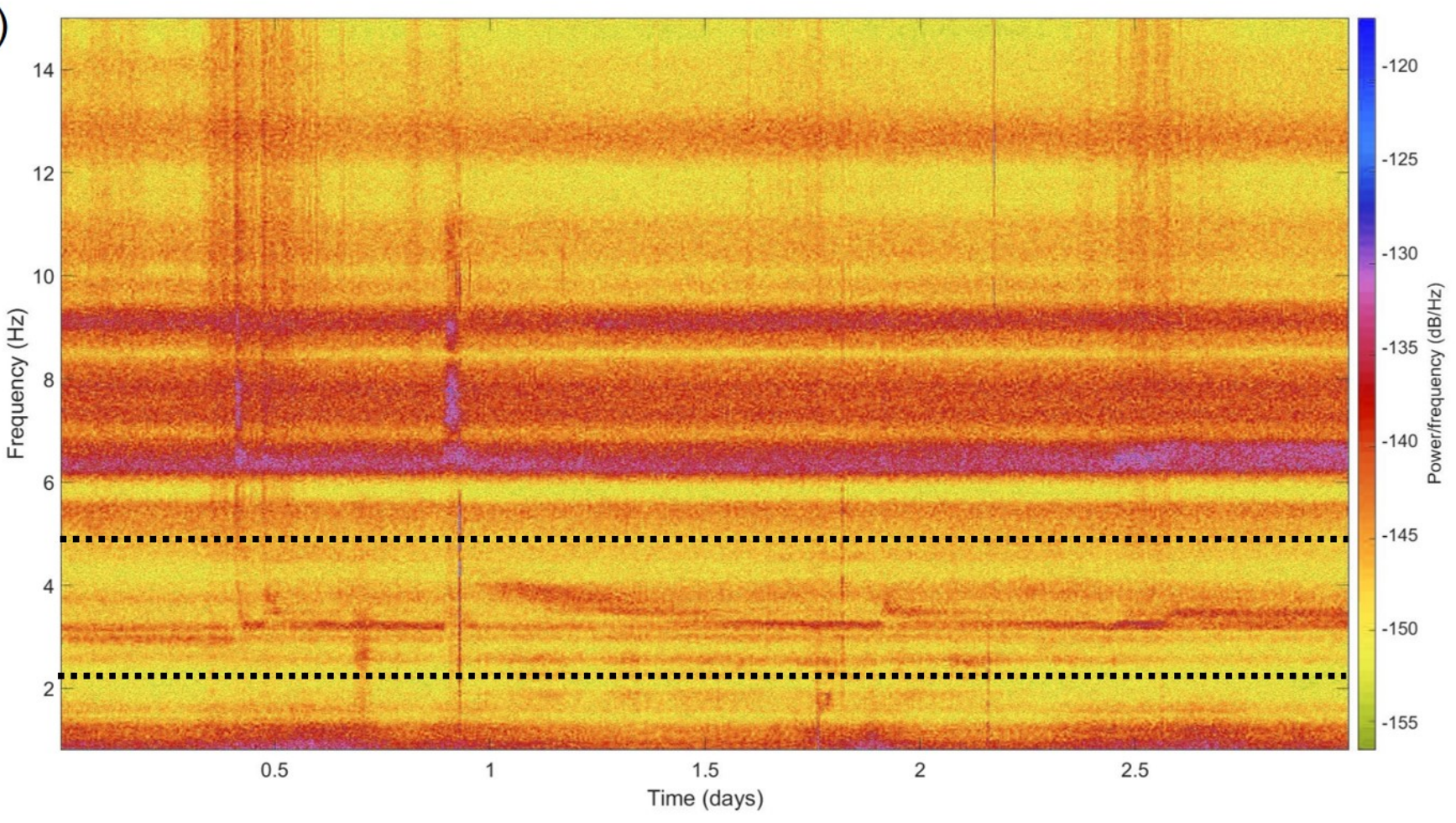

Figure 8: Spectrogram of the ground velocity. (a) CSC north; (b) LKG north. Some relevant fundamental spectral patterns are located between the black dashed lines. Harmonics of these patterns are also visible above, mixed with other patterns. 